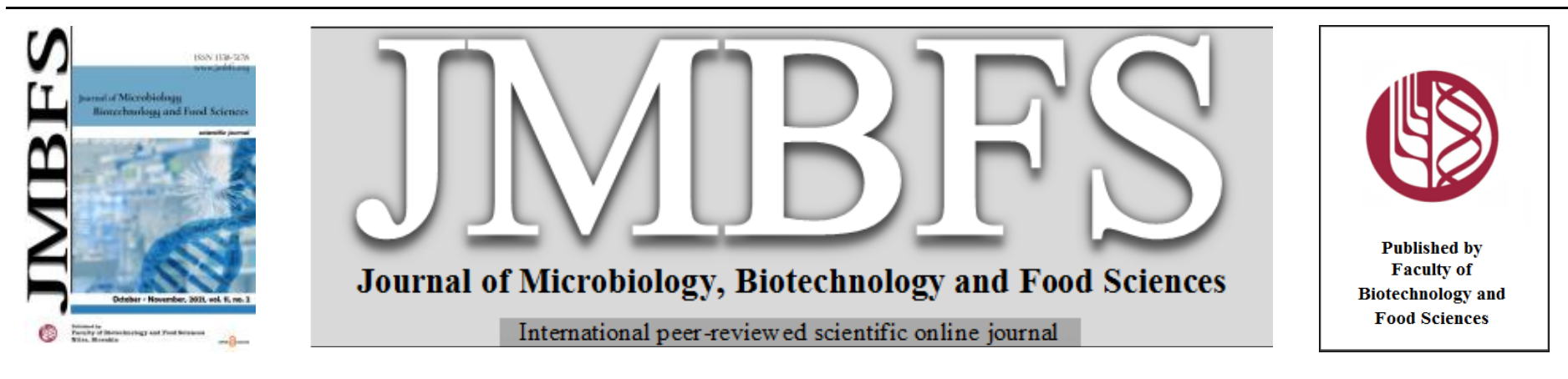

\title{
MYCELIAL INCOMPATIBILITY OF SCLEROTINIA SCLEROTIORUM ISOLATES FROM A SINGLE RAPESEED FIELD IN SLOVAKIA
}

\author{
Monika Tóthová* ${ }^{l}$, Patrícia Máčajovál ${ }^{1}$ Peter Tóth ${ }^{1}$ \\ Address(es): Ing. Monika Tóthová, $\mathrm{PhD}$. \\ ${ }^{1}$ Slovak University of Agriculture in Nitra, Faculty of Agrobiology and Food Resources, Department of Plant Protection, A. Hlinku 2, 94976 Nitra, Slovak Republic, \\ phone number: +421 6414252 .
}

*Corresponding author: monika.tothova@uniag.sk

https://doi.org/10.15414/jmbfs.3369

\section{ARTICLE INFO}

Received 1. 7. 2020

Revised 20. 4. 2021

Accepted 17. 5. 2021

Published 1. 10. 2021

Regular article OPEN OACCESS

\begin{abstract}
Sclerotinia sclerotiorum (Lib.) de Bary (1884) is economically important pathogen of rapeseeds damaging up to $20 \%$ of plants in Slovakia. There is a suggestion that $S$. sclerotiorum reproduces predominantly asexually, thus genetically identical clonal populations are dominating in fields. Genetically distinct isolates can be distinguished by mycelial compatibility-incompatibility grouping system. The aim of the study was to determine genetic variability of S. sclerotiorum based on mycelial interaction within a single oilseed rape field in Slovakia.

S. sclerotiorum isolates were obtained from flower petals of commercial rapeseeds field in Hul, Slovakia (2018) by transferring a single hyphal tip to the plates with potato dextrose agar (PDA). Two sets of 20 isolates were paired in all possible combination and cultivated on PDA amended by bromophenol blue. Mycelial interactions were scored after 7 days.

Each of the 20 isolates in 1st set was unique and belonged to the different mycelial compatibility groups (MCGs). In the 2nd set, 18 MCGs was determined with one isolate and only 1 MCGs consisted of 2 isolates. No prevalent MCG was found in this study, suggesting that $S$. sclerotiorum population affecting the target rapeseed field consisted of a very diverse group of isolates. The high level of incompatible reactions found in this first study from Slovakia may indicate that $S$. sclerotiorum undergoes frequent outcrossing in rapeseed stands.
\end{abstract}

Keywords: mycelial compatibility groups, mycelial interactions, Sclerotinia sclerotiorum, rapeseeds, genetic diversity

\section{INTRODUCTION}

In 2019, rapeseed (Brassica napus L.) was grown on an area of about 147,000.00 ha (11\% of arable land area) in Slovakia (ŠÚ SR, 2020). Sclerotinia sclerotiorum (Lib.) de Bary (1884) is one of its economically most important pathogens damaging up to $20 \%$ of plants in years with higher precipitation during flowering (Bokor and Bečka, 2017)

Patterns of pathogen's genetic diversity are likely affected by modes of reproduction (Aldrich-Wolfe and Nelson, 2015). Previous studies have suggested that homothallic S. sclerotiorum reproduces predominantly asexually and in fields is dominated by clonal populations that are genetically identical (Kohli et al. 1992). Genetically distinct isolates can be easily distinguished by a quick and inexpensive macroscopic assay of the self-nonself recognition method followed by inclusion them into mycelial compatibility-incompatibility groups (Kohn et al., 1990). Mycelial compatibility is the ability of two strains of filamentous fungi to anastomose and form one confluent colony. Different mycelial compatibility groups (MCGs) represent genetically distinct isolates (Kohn et al., 1991).

Data of the Kohn et al. (1991) demonstrate that the mycelial incompatibility in $S$. sclerotiorum occurs even within a local field population. Since there is no information available on MCGs of the $S$. sclerotinia populations in rapeseed fields in Slovakia, the aim of the study was to determine genetic variability of $S$. sclerotiorum based on mycelial interaction within a single oilseed rape field.

\section{MATERIAL AND METHODS}

Isolates of S. sclerotiorum were obtained from flower petals of commercial rapeseeds field. Fresh flower petals were sampled randomly along the diagonal direction in the target field. Collected flower petals were transported to the laboratory in paper bags and immediately cultivated on potato dextrose agar (PDA) at room temperature for 7 days. Four flower petals without surface sterilization were placed to each plate $(90 \mathrm{~mm}$ in diameter). A total 40 isolates were purified by transferring a mycelial plug $(6 \mathrm{~mm}$ in diameter) followed by transferring of the single hyphal tip 3 times to the plates with PDA. Hyphal segments were cut using a small needle under a binocular microscope in interval of $24-48$ hours. Identification of S. sclerotiorum isolates was based on morphology of the mycelial mat and sclerotia formation traits. All isolates collected in 2018 originated from the same crop located in Hul, Nitra Region, Slovakia.

Mycelial compatibility grouping was determined according to the Schafer and Kohn (2006) with modification. Isolates were grown on PDA for 5 days in dark at the temperature of $20 \pm 2^{\circ} \mathrm{C}$. Mycelial plugs of two strains $(6 \mathrm{~mm}$ in diameter), obtained at least $10 \mathrm{~mm}$ inside from the growing edge of the colony, were placed in Petri dish (90 mm in diameter) $30 \mathrm{~mm}$ apart. Mycelial plugs were cultivated on PDA amended with bromophenol blue $50 \mathrm{mg} \cdot \mathrm{L}^{-1}$. Bromophenol blue was added to enhance the visibility of incompatible reaction. Pairing plates were incubated in dark at the temperature of $20 \pm 2^{\circ} \mathrm{C}$. Compatible and incompatible reactions were scored after 7 days. Compatibility occurred when no reaction line occurred in interaction zone, and the pairings formed one confluent colony. Incompatible pairings formed a visible reaction in interaction zone such a yellow to green line visible on the colony reverse, or a band of sparse aerial mycelium on colony surface.

Two sets of isolates were paired in all possible combination. Each set consisted of 20 isolates and 190 combinations. Each isolate was paired by itself as a control of compatibility. Experiment was repeated three times. In case of inconsistent results, the assay was repeated once more.

\section{RESULTS}

Flower petal isolates of $S$. sclerotiorum obtained from a single rapeseed field were compared with each other in two sets. Each of the 20 isolates in $1^{\text {st }}$ set was unique and belonged to the different MCGs (Table 1). In the $2^{\text {nd }}$ set, 18 MCGs was determined with one isolate and only 1 MCG consisted of 2 isolates (Table 2). No prevalent MCG was found in this study, suggesting that S. sclerotiorum population affecting the target rapeseed field consisted of a very diverse group of isolates.

Of the 190 combinations, the most pairings (136 in $1^{\text {st }}$ set and 151 in $2^{\text {nd }}$ set) showed incompatible reaction with dark mycelium and/or green-yellow line in 
interaction zone on the colony reverse (Figure $3-4$ ). Only isolate 295 (2nd set) gave this single type of incompatible reaction in combination with all pairings. Rest of the combinations showed modest form of incompatible reaction - a band of sparse aerial mycelium on colony surface (Figure 2); and as mentioned above,
2 isolates $(287 \times 336)$ in $2^{\text {nd }}$ set were compatible. All self-pairings gave a compatible reaction (Table $1-2$, Figure 1).

Table 1 First set of Sclerotinia sclerotiorum flower petal isolates obtained from a single rapeseed field in Hul, Slovakia in 2018

\begin{tabular}{|c|c|c|c|c|c|c|c|c|c|c|c|c|c|c|c|c|c|c|c|c|}
\hline & 340 & 342 & 347 & 355 & 358 & 362 & 364 & 370 & 373 & 377 & 382 & 383 & 386 & 388 & 391 & 394 & 396 & 400 & 403 & 404 \\
\hline 340 & $\square$ & $\bullet$ & $\bullet$ & $\bullet$ & $\bullet$ & 0 & $\bullet$ & $\bullet$ & $\bullet$ & $\bullet$ & 0 & 0 & $\bullet$ & 0 & $\bullet$ & $\bullet$ & $\bullet$ & $\bullet$ & $\bullet$ & $\bullet$ \\
\hline 342 & & $\square$ & $\bullet$ & $\bullet$ & $\bullet$ & $\bullet$ & $\bullet$ & 0 & $\bullet$ & $\circ$ & $\bullet$ & $\bullet$ & $\bullet$ & $\bullet$ & $\bullet$ & $\circ$ & $\circ$ & $\circ$ & $\bullet$ & $\bullet$ \\
\hline 347 & & & $\square$ & $\bullet$ & $\bullet$ & $\bullet$ & $\bullet$ & $\bullet$ & $\bullet$ & $\bullet$ & $\bullet$ & $\bullet$ & $\bullet$ & $\bullet$ & $\circ$ & 0 & $\bullet$ & $\bullet$ & $\bullet$ & 0 \\
\hline 355 & & & & $\square$ & $\bullet$ & $\bullet$ & $\bullet$ & - & $\bullet$ & $\bullet$ & $\bullet$ & $\bullet$ & $\bullet$ & $\circ$ & $\circ$ & 0 & $\bullet$ & $\bullet$ & $\bullet$ & $\bullet$ \\
\hline 358 & & & & & $\square$ & $\bullet$ & 0 & $\bullet$ & $\bullet$ & $\bullet$ & $\bullet$ & $\bullet$ & $\bullet$ & 0 & $\bullet$ & $\bullet$ & $\bullet$ & $\bullet$ & $\bullet$ & $\bullet$ \\
\hline 362 & & & & & & $\square$ & $\circ$ & $\bullet$ & $\bullet$ & $\bullet$ & $\bullet$ & 0 & $\bullet$ & 0 & $\bullet$ & $\bullet$ & $\bullet$ & $\bullet$ & $\bullet$ & $\bullet$ \\
\hline 364 & & & & & & & $\square$ & $\bullet$ & $\bullet$ & $\bullet$ & 0 & 0 & 0 & 0 & $\bullet$ & $\bullet$ & $\bullet$ & $\bullet$ & $\bullet$ & $\bullet$ \\
\hline 370 & & & & & & & & $\square$ & $\circ$ & $\bullet$ & $\bullet$ & $\bullet$ & $\circ$ & $\circ$ & $\bullet$ & $\bullet$ & $\bullet$ & $\bullet$ & $\bullet$ & $\bullet$ \\
\hline 373 & & & & & & & & & $\square$ & $\bullet$ & $\bullet$ & $\bullet$ & $\bullet$ & $\circ$ & $\bullet$ & $\circ$ & $\bullet$ & $\bullet$ & $\bullet$ & $\circ$ \\
\hline 377 & & & & & & & & & & $\square$ & $\bullet$ & $\bullet$ & $\bullet$ & $\bullet$ & $\bullet$ & $\bullet$ & $\bullet$ & $\bullet$ & $\bullet$ & $\bullet$ \\
\hline 382 & & & & & & & & & & & $\square$ & $\bullet$ & $\bullet$ & 0 & $\bullet$ & $\bullet$ & $\bullet$ & $\bullet$ & $\bullet$ & $\bullet$ \\
\hline 383 & & & & & & & & & & & & $\square$ & $\bullet$ & 0 & $\bullet$ & $\bullet$ & $\bullet$ & $\bullet$ & $\bullet$ & $\circ$ \\
\hline 386 & & & & & & & & & & & & & $\square$ & 0 & $\bullet$ & $\bullet$ & 0 & $\bullet$ & 0 & 0 \\
\hline 388 & & & & & & & & & & & & & & $\square$ & $\circ$ & 0 & $\bullet$ & 0 & 0 & 0 \\
\hline 391 & & & & & & & & & & & & & & & $\square$ & $\circ$ & $\circ$ & $\circ$ & $\circ$ & $\bullet$ \\
\hline 394 & & & & & & & & & & & & & & & & ㅁ & $\circ$ & $\circ$ & $\circ$ & $\circ$ \\
\hline 396 & & & & & & & & & & & & & & & & & $\square$ & 0 & 0 & $\circ$ \\
\hline 400 & & & & & & & & & & & & & & & & & & $\square$ & $\bullet$ & $\circ$ \\
\hline 403 & & & & & & & & & & & & & & & & & & & $\square$ & $\bullet$ \\
\hline 404 & & & & & & & & & & & & & & & & & & & & $\square$ \\
\hline
\end{tabular}

Legend:

$\square$ compatible reaction

$\circ$ incompatible reaction with a band of sparse aerial mycelium in the interaction zone

- incompatible reaction with dark mycelium and / or green-yellow line in interaction zone

Table 2 Second set of Sclerotinia sclerotiorum flower petal isolates obtained from a single rapeseed field in Hul, Slovakia in 2018

\begin{tabular}{|l|l|l|l|l|l|l|l|l|l|l|l|l|l|l|l|l|l|l|l|l|l|l|}
\hline & 269 & 272 & 277 & 280 & 282 & 287 & 290 & 291 & 295 & 297 & 299 & 303 & 308 & 309 & 318 & 320 & 323 & 329 & 333 & 336 \\
\hline 269 & $\square$ & $\bullet$ & $\bullet$ & $\bullet$ & $\bullet$ & $\circ$ & $\circ$ & $\bullet$ & $\bullet$ & $\circ$ & $\circ$ & $\bullet$ & $\bullet$ & $\bullet$ & $\bullet$ & $\bullet$ & $\bullet$ & $\circ$ & $\bullet$ & $\circ$ \\
\hline 272 & & $\square$ & $\circ$ & $\bullet$ & $\circ$ & $\bullet$ & $\bullet$ & $\bullet$ & $\bullet$ & $\bullet$ & $\bullet$ & $\bullet$ & $\bullet$ & $\bullet$ & $\bullet$ & $\bullet$ & $\bullet$ & $\bullet$ & $\bullet$ & $\bullet$ \\
\hline 277 & & & $\square$ & $\circ$ & $\circ$ & $\bullet$ & $\bullet$ & $\bullet$ & $\bullet$ & $\circ$ & $\bullet$ & $\bullet$ & $\bullet$ & $\bullet$ & $\bullet$ & $\bullet$ & $\circ$ & $\bullet$ & $\bullet$ & $\bullet$ \\
\hline 280 & & & & $\square$ & $\circ$ & $\bullet$ & $\bullet$ & $\circ$ & $\bullet$ & $\bullet$ & $\bullet$ & $\bullet$ & $\bullet$ & $\circ$ & $\bullet$ & $\circ$ & $\circ$ & $\bullet$ & $\circ$ & $\bullet$ \\
\hline 282 & & & & & $\square$ & $\bullet$ & $\bullet$ & $\circ$ & $\bullet$ & $\bullet$ & $\bullet$ & $\bullet$ & $\bullet$ & $\bullet$ & $\circ$ & $\circ$ & $\circ$ & $\bullet$ & $\circ$ & $\bullet$ \\
\hline 287 & & & & & & $\square$ & $\bullet$ & $\bullet$ & $\bullet$ & $\circ$ & $\circ$ & $\bullet$ & $\bullet$ & $\bullet$ & $\bullet$ & $\bullet$ & $\bullet$ & 0 & $\bullet$ & $\square$ \\
\hline 290 & & & & & & & $\square$ & $\bullet$ & $\bullet$ & $\bullet$ & $\bullet$ & $\bullet$ & $\bullet$ & $\bullet$ & $\bullet$ & $\bullet$ & $\bullet$ & 0 & $\bullet$ & $\bullet$ \\
\hline 291 & & & & & & & & $\square$ & $\bullet$ & $\bullet$ & $\bullet$ & $\bullet$ & $\bullet$ & $\bullet$ & $\bullet$ & $\bullet$ & $\bullet$ & $\bullet$ & $\bullet$ & $\bullet$ \\
\hline 295 & & & & & & & & & $\square$ & $\bullet$ & $\bullet$ & $\bullet$ & $\bullet$ & $\bullet$ & $\bullet$ & $\bullet$ & $\bullet$ & $\bullet$ & $\bullet$ & $\bullet$ \\
\hline 297 & & & & & & & & & & $\square$ & $\circ$ & $\bullet$ & $\bullet$ & $\bullet$ & $\circ$ & $\bullet$ & $\bullet$ & 0 & $\bullet$ & $\bullet$ \\
\hline 299 & & & & & & & & & & & $\square$ & $\bullet$ & $\bullet$ & $\bullet$ & $\circ$ & $\bullet$ & $\bullet$ & $\circ$ & $\bullet$ & $\bullet$ \\
\hline 303 & & & & & & & & & & & & $\square$ & $\bullet$ & $\bullet$ & $\circ$ & $\bullet$ & $\bullet$ & $\bullet$ & $\bullet$ & $\bullet$ \\
\hline 308 & & & & & & & & & & & & & $\square$ & $\circ$ & $\bullet$ & $\bullet$ & $\bullet$ & $\circ$ & $\bullet$ & $\bullet$ \\
\hline 309 & & & & & & & & & & & & & & $\square$ & $\bullet$ & $\bullet$ & $\bullet$ & $\bullet$ & $\bullet$ & $\bullet$ \\
\hline 318 & & & & & & & & & & & & & & & $\square$ & $\bullet$ & $\bullet$ & $\circ$ & $\circ$ & $\circ$ \\
\hline 320 & & & & & & & & & & & & & & & & $\square$ & $\bullet$ & $\bullet$ & $\bullet$ & $\bullet$ \\
\hline 323 & & & & & & & & & & & & & & & & & $\square$ & $\bullet$ & $\bullet$ & $\bullet$ \\
\hline 329 & & & & & & & & & & & & & & & & & & $\square$ & $\bullet$ & $\bullet$ \\
\hline 333 & & & & & & & & & & & & & & & & & & & $\square$ & $\bullet$ \\
\hline 336 & & & & & & & & & & & & & & & & & & & & $\square$ \\
\hline
\end{tabular}

Legend:

$\square$ compatible reaction

o incompatible reaction with a band of sparse aerial mycelium in the interaction zone

- incompatible reaction with dark mycelium and / or green-yellow line in interaction zone

\section{DISCUSSION}

In this study we assumed a presence of a clonal population with at least one prevalent MCG from the single rapeseed field. The reason of this assumption was that homothalic fungi as $S$. sclerotiorum are reproducing predominantly by haploid selfing (Kohn, 1995), what is functionally equivalent to clonal reproduction (Attanayake at al., 2014). Our assumptions were not confirmed, as the target rapeseed field consisted of a very diverse group of isolates mostly incompatible with each other. Since classification of isolates into MCGs is routinely used as a quick marker for genotyping of S. sclerotiorum (Schafer and Kohn, 2006) and a sexual recombination is the main source of genotypic variations (Attanayake at al., 2014), our results may indicate the occurrence of highly recombinant population with limited presence of clonality in the single field during the sampled year. Mechanisms of the widespread genetic recombination in homothallic species are still obscure (Attanayake et al., 2019). One of the possibilities is the forming of sclerotia from hyphae of different genotype resulting in recombinant ascospores (Sexton et al., 2006). Single sclerotium from Brazilian common bean comprised of $1-5$ distinct haplotypes (Lehner et al., 2015), while single sclerotium from Australian sunflower comprised of only one genotype, despite of infections containing multiple genotypes (Ekins et al., 2010)

Our isolates were obtained from flower petals of rapeseeds contaminated or infected by ascospores. Ascospores released during flowering are considered as the main source of inoculum for rapeseeds infections. In Australian rapeseeds field was not found significant population subdivision between the ascospore and stem lesion populations, suggesting that there are no genetically defined subgroup of isolates causing stem infections (Sexton et al., 2006).

Many of our pairings showed incompatible reaction with dark mycelium in interaction zone. Fungal colonies of different isolates often display melanization due to hyphal killing or lysis in the zone between them (Henson et al., 1999). Karimi et al. (2012) in their study distinguished 3 levels of incompatible reactions - partial compatibility, intermediate incompatibility, and complete incompatibility. Kohn et al. (1990) scored pairings into the 5-type of incompatible reactions. The strong incompatible reactions given by the presence of dark melanised mycelium in interaction zone were not mentioned in any of these studies. 


\section{CONCLUSION}

No prevalent mycelial compatibility group was found in this study, suggesting that $S$. sclerotiorum population affecting the target rapeseed field consisted of a very diverse group of isolates. The high level of incompatible reactions found in this first preliminary study from Slovakia should be in line with findings that $S$ sclerotiorum, in addition to haploid selfing and clonal sclerotial production, undergoes frequent outcrossing in nature (Attanayake et al., 2014). However, to support this finding, there is a need for more extent research from larger geographical area and different host plant.

Acknowledgements: This work was supported by the Operational Program Integrated Infrastructure within the project Sustainable smart farming systems taking into account the future challenges (ITMS 313011W112), co-financed by the European Regional Development Fund.

\section{REFERENCES}

Aldrich-Wolfe, L., Travers, S., \& Nelson, B. D. (2015). Genetic Variation of Sclerotinia sclerotiorum from Multiple Crops in the North Central United States. PLOS ONE, 10(9), e0139188. https://doi.org/10.1371/journal.pone.0139188 Attanayake, R. N., Tennekoon, V., Johnson, D. A., Porter, L. D., del RíoMendoza, L., Jiang, D., \& Chen, W. (2014). Inferring outcrossing in the homothallic fungus Sclerotinia sclerotiorum using linkage disequilibrium decay. Heredity, 113(4), 353-363. https://doi.org/10.1038/hdy.2014.37

Attanayake, R. N., Xu, L., \& Chen, W. (2019). Sclerotinia sclerotiorum populations: clonal or recombining? Tropical Plant Pathology, 44(1), 23-31. https://doi.org/10.1007/S40858-018-0248-7

Bokor, P. \& Bečka, D. (2017). Zdravotný stav repky ozimnej v poloprevádzkových pokusoch v roku 2017 na Slovensku [Health status of winter rapeseed under semi-practice experiments during 2017 in Slovakia]. In Prosperujíci olejniny 2017. Praha: Česká zemědělská univerzita, 2017, p. 107 110. ISBN 978-80-213-2798-6.

Ekins, M. G., Hayden, H. L., Aitken, E. A. B., \& Goulter, K. C. (2010). Population structure of Sclerotinia sclerotiorum on sunflower in Australia Australasian Plant Pathology, 40(2), 99-108. https://doi.org/10.1007/s13313-0100018-6

Henson, J. M., Butler, M. J., \& Day, A. W. (1999). The Darkside of the Mycelium: Melanins of Phytopathogenic Fungi. Annual Review of Phytopathology, 37(1), 447-471. https://doi.org/10.1146/annurev.phyto.37.1.447 Karimi, E., Safaie, N., \& Shams-bakhsh, M. (2012). Mycelial compatibility groupings and pathogenic diversity of Sclerotinia sclerotiorum (Lib.) de Bary populations on canola in Golestan Province of Iran. Journal of Agricultural Science and Technology, 14, 421-434.

Kohli, Y. (1992). Local and Trans-Canadian Clonal Distribution of Sclerotinic $\begin{array}{llll}\text { sclerotiorum on Canola. Phytopathology, } & 82(8),\end{array}$ https://doi.org/10.1094/phyto-82-875

Kohn, L. M. (1995). The clonal dynamic in wild and agricultural plant-pathogen populations. Canadian Journal of Botany, 73(S1), 1231-1240 https://doi.org/10.1139/b95-383

Kohn, L. M., Carbone, I., \& Anderson, J. B. (1990). Mycelial interactions in Sclerotinia sclerotiorum. Experimental mycology, 14(3), 255-267. https://doi.org/10.1016/0147-5975(90)90023-M

Kohn, L. M., Stasovski, E., Carbone, I., Royer, J., \& Anderson, J. B. (1991) Mycelial incompatibility and molecular markers identify genetic variability in field populations of Sclerotinia sclerotiorum. Phytopathology, 81(4), 480-485 https://doi.org/10.1094/phyto-81-480

Lehner, M. S., Paula Júnior, T. J., Hora Júnior, B. T., Teixeira, H., Vieira, R. F., Carneiro, J. E. S., \& Mizubuti, E. S. G. (2015). Low genetic variability in Sclerotinia sclerotiorum populations from common bean fields in Minas Gerais State, Brazil, at regional, local and micro-scales. Plant Pathology, 64(4), 921931. https://doi.org/10.1111/ppa.12322

Schafer, M. R.. \& Kohn, L. M. (2006). An optimized method for mycelial compatibility testing in Sclerotinia sclerotiorum. Mycologia, 98(4), 593-597. https://doi.org/10.1080/15572536.2006.11832662

Sexton, A., Whitten, A.R., \& Howlett, B.J. (2006). Population structure of Sclerotinia sclerotiorum in an Australian canola field at flowering and stem infection stages of the disease cycle. Genome, 49 11, 1408-15 https://doi.org/10.1139/g06-101

ŠÚ SR. (2020). STATdat. Public database [online database]. [cit. 2020-05-25]. Available at: <http://statdat.statistics.sk>

\section{SUPPLEMENTARY FIGURES}

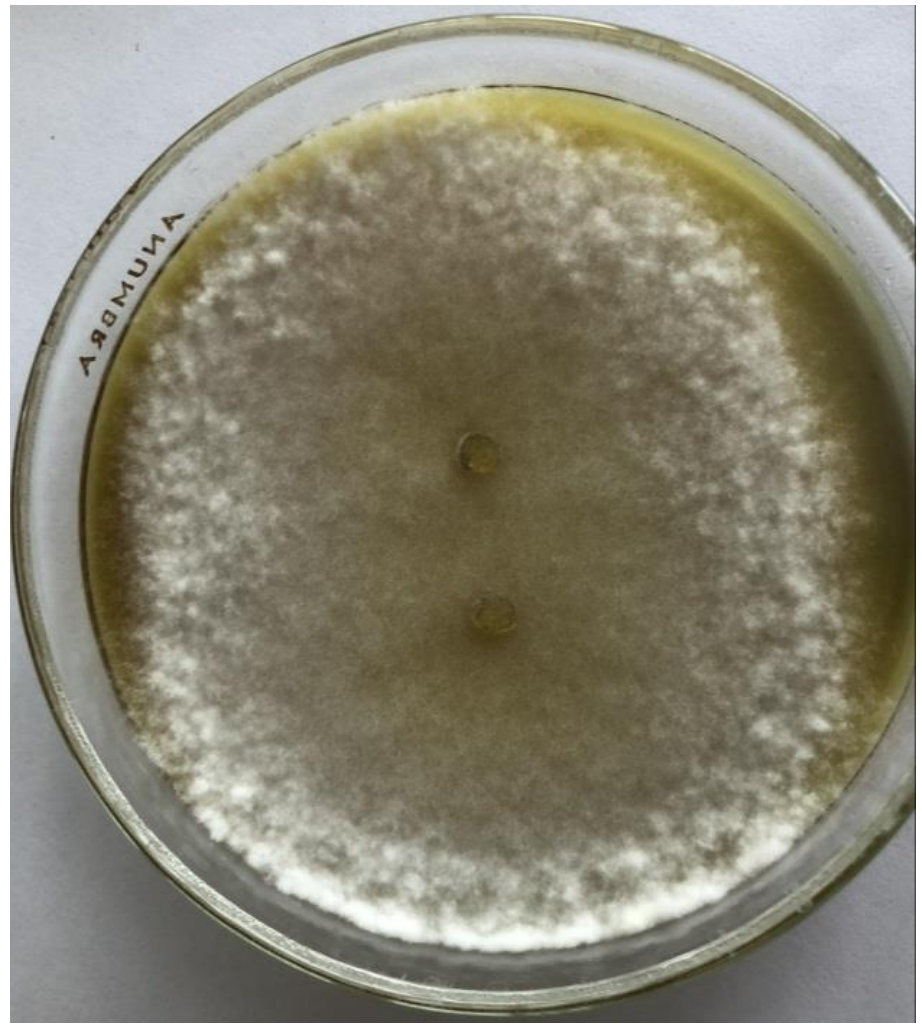

Figure 1 Compatible reaction in pairings between the same flower petal isolate of Sclerotinia sclerotiorum (isolates $391 \times 391$ )

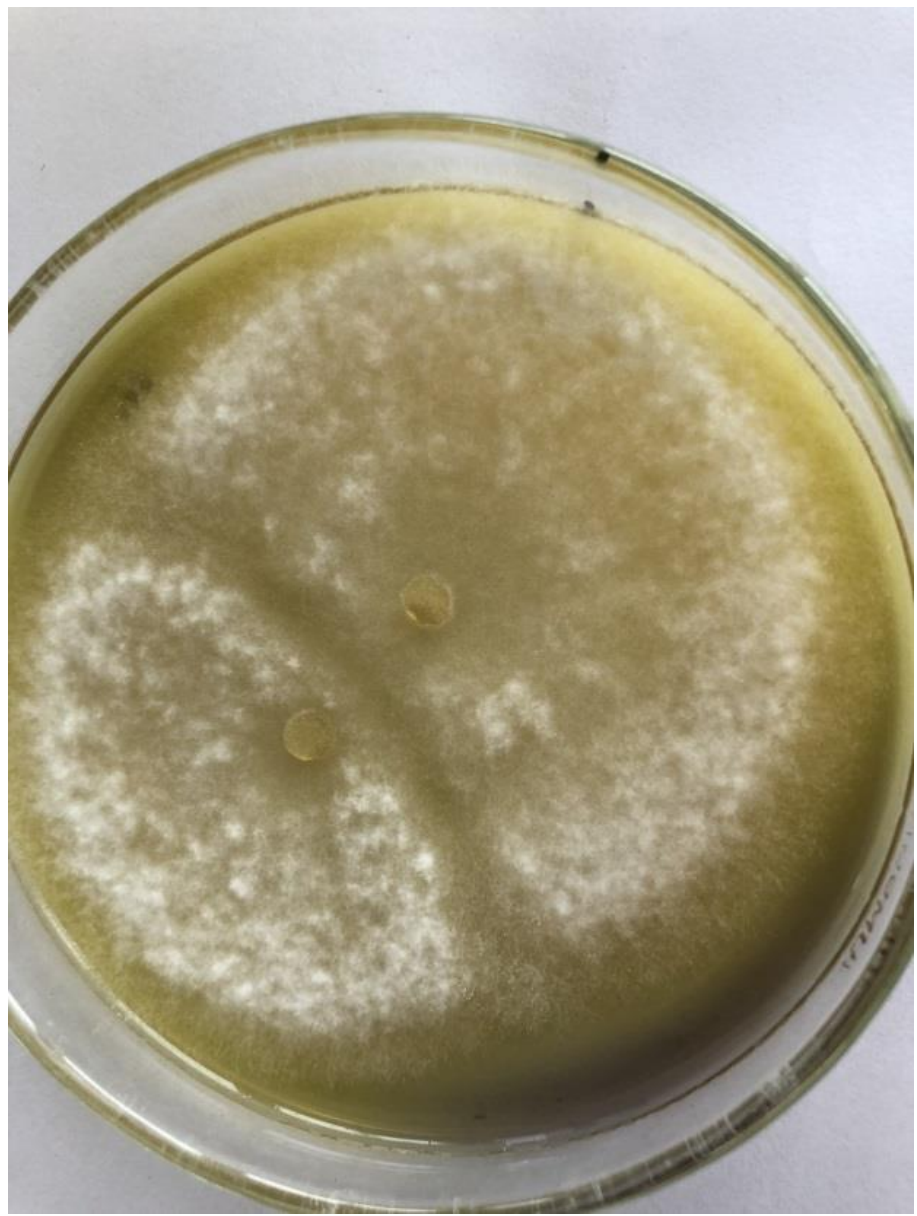

Figure 2 Incompatible reaction with thin a band of sparse aerial mycelium in the interaction zone in pairings between different flower petal isolates of Sclerotinia sclerotiorum (isolates $391 \times 394$ ) 


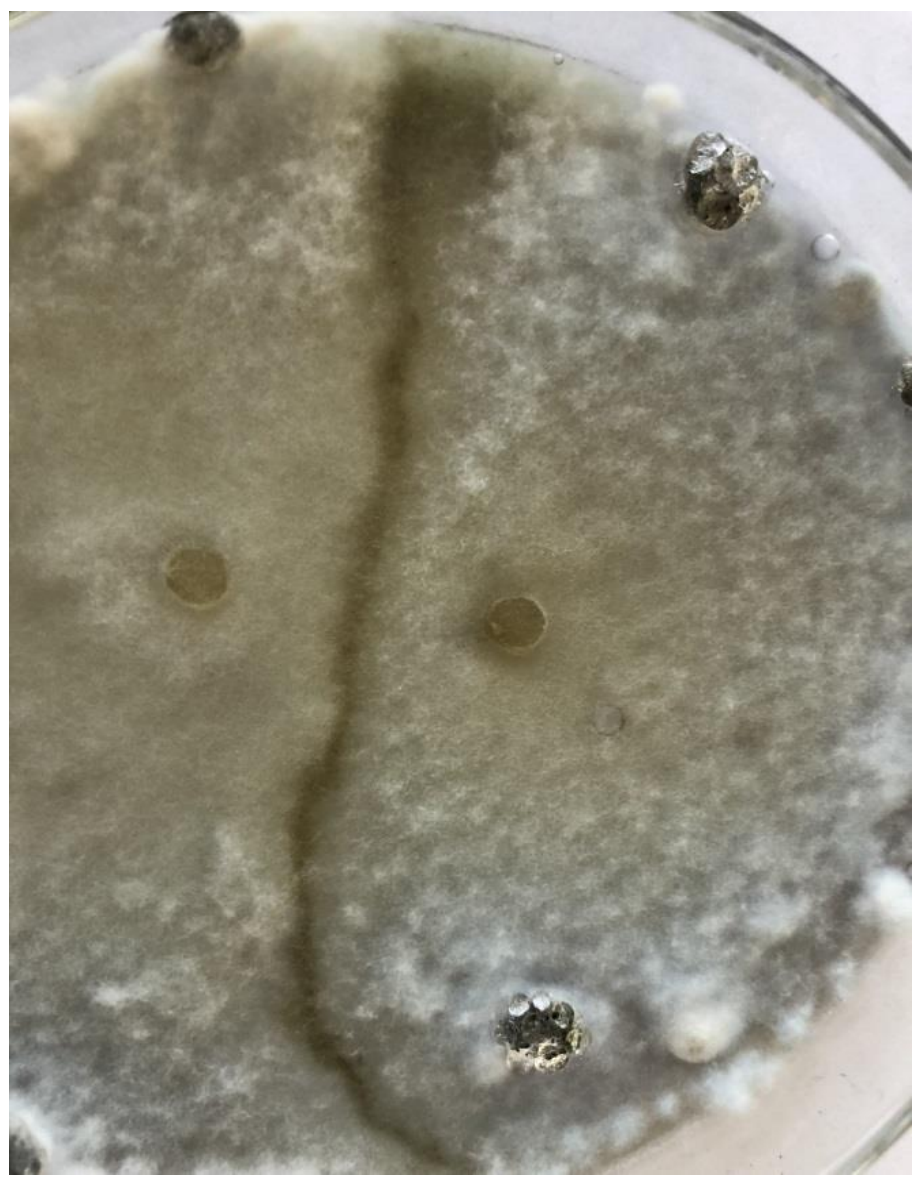

Figure 3 Incompatible reaction with dark mycelium in interaction zone in pairings between different flower petal isolates of Sclerotinia sclerotiorum (isolates $382 \times 396$ )

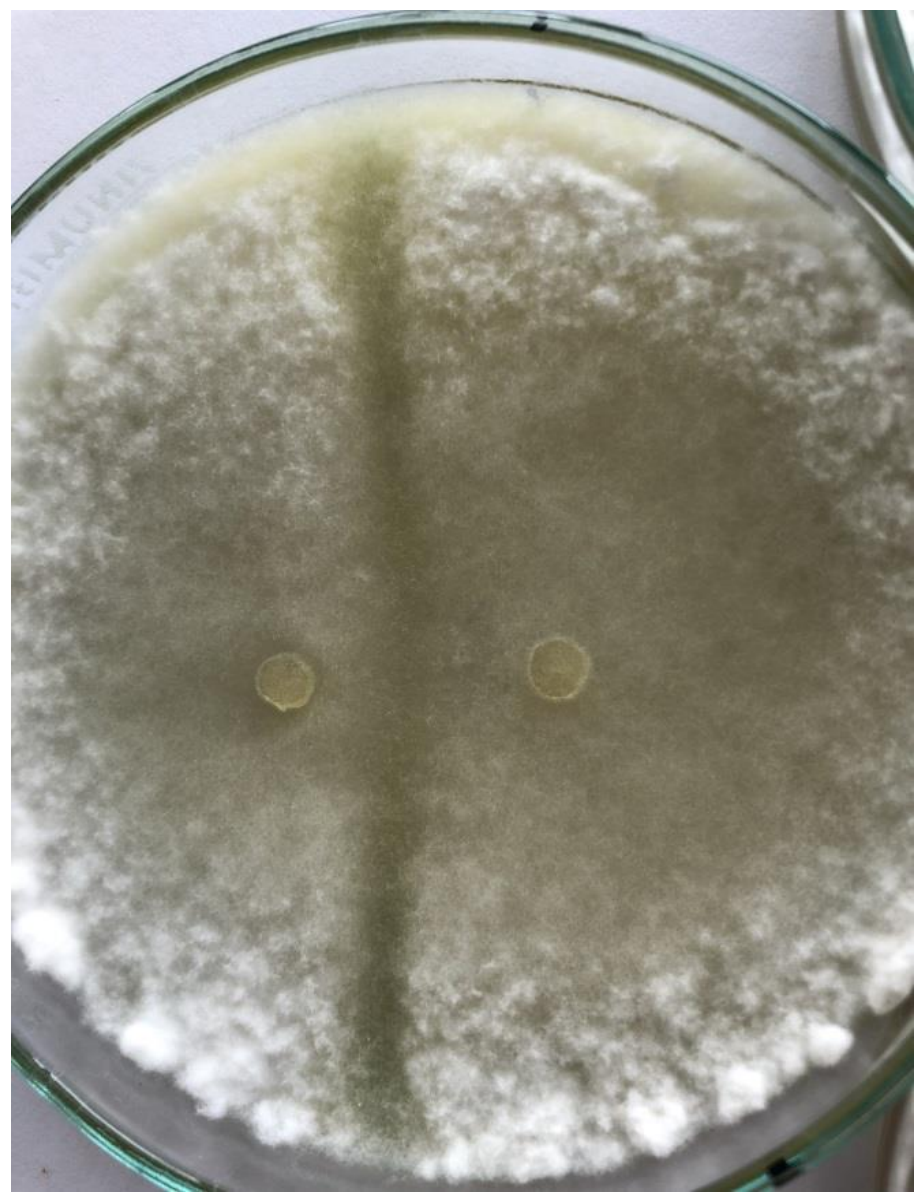

Figure 4 Incompatible reaction with green-yellow line in interaction zone in pairings between different flower petal isolates of Sclerotinia sclerotiorum (isolates $377 \times 403$ ) 